\title{
IL-8 is upregulated in cervical cancer tissues and is associated with the proliferation and migration of HeLa cervical cancer cells
}

\author{
LINLIN JIA $^{1^{*}}$, FENGYING LI $^{2^{*}}$, MINGLIANG SHAO $^{3}$, WEI ZHANG $^{3}$, CHUNBIN ZHANG $^{1}$, XIAOLIAN ZHAO $^{1}$, \\ HAIYAN LUAN ${ }^{1}$, YALING QI ${ }^{1}$, PENGXIA ZHANG ${ }^{1}$, LICHUN LIANG ${ }^{1}$, XIUYUE JIA ${ }^{1}$, KUN ZHANG ${ }^{1}$, \\ YAN LU ${ }^{1}$, ZHE YANG $^{1}$, XIULIN ZHU ${ }^{1}$, QI ZHANG ${ }^{1}$, JIWEI DU ${ }^{4}$ and WEIQUN WANG ${ }^{1}$ \\ ${ }^{1}$ Department of Physiology, Basic Medical College, Jiamusi University, Jiamusi, Heilongjiang $154007 ;{ }^{2}$ Department of \\ Obstetrics and Gynecology, Maternity and Infant Hospital of Jiamusi, Jiamusi, Heilongjiang $154002{ }^{3}$ Department of \\ Interventional Medicine, The Fifth Hospital, Shijiazhuang, Hebei 050021; ${ }^{4}$ Nursing Department, \\ The First Affiliated Hospital, Jiamusi University, Jiamusi, Heilongjiang 154002, P.R. China
}

Received November 9, 2016; Accepted September 22, 2017

DOI: $10.3892 / \mathrm{ol} .2017 .7391$

\begin{abstract}
Interleukin-8 (IL-8) serves an important function in chronic inflammation and cancer development; however, the underlying molecular mechanism(s) of IL-8 in uterine cervical cancer remains unclear. The present study investigated whether IL-8 and its receptors [IL-8 receptor (IL-8R)A and IL-8RB] contributed to the proliferative and migratory abilities of HeLa cervical cancer cells, and also investigated the potential underlying molecular mechanisms. Results demonstrated that IL- 8 and its receptors were detected in HeLa cells, and levels of IL-8RA were significantly increased compared with those of IL-8RB. Furthermore, the level of IL- 8 in cervical cancer tissues was significantly increased compared with that in normal uterine cervical tissues, and migratory and proliferative efficiencies of HeLa cells treated with exogenous IL-8 were increased, compared with untreated HeLa cells. In addition, exogenous IL-8 was able to downregulate endocytic adaptor protein (NUMB), and upregulate IL-8RA, IL-8RB and extracellular signal-regulated protein kinases (ERKs) expression levels in HeLa cells. Results suggest that IL-8 and its receptors were associated with the tumorigenesis of uterine cervical cancer, and exogenous IL-8 promotes the carcinogenic
\end{abstract}

Correspondence to: Professor Weiqun Wang, Department of Physiology, Basic Medical College, Jiamusi University, 148 Xuefu Street, Jiamusi, Heilongjiang 154007, P.R. China

E-mail: wangweiqun1974@163.com

Professor Jiwei Du, Nursing Department, The First Affiliated Hospital, Jiamusi University, 348 Dexiang Street, Jiamusi, Heilongjiang 154002, P.R. China

E-mail: dujiwei1977@163.com

${ }^{*}$ Contributed equally

Key words: uterine cervical cancer, interleukin-8, interleukin-8 receptor, extracellular-signal-regulated kinase, endocytic adaptor protein potential of HeLa cells by increasing the expression levels of IL-8RA, IL-8RB and ERK, and decreasing the expression level of NUMB.

\section{Introduction}

Uterine cervical cancer (UCC) is the most commonly diagnosed cancer, and a leading cause of cancer-associated mortality for women in developing countries, including China (1). Despite improvements in diagnostics and therapeutic strategies, the prognosis of UCC remains poor (2). The World Health Organization estimates that the prevalence of UCC annually is $\sim 530,000$ cases worldwide, and $\sim 50 \%$ of patients succumb to the disease (1). The pathophysiology of UCC is complex because of multiple risk factors including viral infection, premature childbirth, inflammation and high estrogen levels (3). Therefore, an improved understanding of the initiation and progression of UCC is required for a timely diagnosis, prevention and therapeutic intervention (4).

Interleukins (ILs) are produced by many types of cells and collectively they cause a variety of biological effects, which are exerted on the immune response and include maturation, activation and proliferation of immune cells (5). Previous studies have demonstrated that ILs also contribute an important function in tumor development and metastasis via autocrine and/or paracrine signaling $(6,7)$. Interleukin-8 [IL-8 or CXC chemokine ligand 8 (CXCL8)], a cytokine family member, has previously been demonstrated to contribute to chronic inflammation and cancer development via several signaling transduction pathways $(8,9)$. IL- 8 derived from cancer cells is able to promote the capacity of cellular proliferation, adhesion, migration, invasion, chemoresistance and angiogenesis by binding to its corresponding receptor in several types of carcinoma, indicating that IL-8 may serve as a therapeutic target for malignant tumors $(10,11)$. However, the precise function of IL-8 and its clinical significance in malignancy remain unclear.

In the present study, levels of IL-8 and its receptors IL-8 receptor A (IL-8RA) and IL-8 receptor B (IL-8RB) in HeLa cells were investigated, and the differences in the expression levels of IL-8 in normal uterine cervical tissues and UCC 
tissues were compared. The effect of exogenous IL-8 on the proliferation and migration in HeLa cells, and the exact mechanism by which IL-8 enhanced the oncogenic potential of UCC was also investigated. The aim of the present study was to clarify the function of IL-8 and its receptors in UCC, and therefore provide a novel biomarker for the diagnosis and treatment of UCC.

\section{Materials and methods}

Cell culture. The human cervical carcinoma immortalized cell line HeLa was obtained from the American Type Culture Collection (Manassas, VA, USA). Cells were maintained in RPMI-1640 medium (Gibco; Thermo Fisher Scientific, Inc., Waltham, MA, USA) and supplemented with $10 \%$ fetal bovine serum (FBS; Gibco; Thermo Fisher Scientific, Inc.) and penicillin-streptomycin (100 units/ml) under standard culture conditions (12).

mRNA expression of genes in HeLa cells using the reverse transcription-polymerase chain reaction (RT-PCR). Following isolation of total RNA from HeLa cells using TRIzol reagent (Invitrogen; Thermo Fisher Scientific, Inc.), cDNA was prepared using $2 \mu \mathrm{g}$ total RNA reverse-transcribed using a Quant Reverse Transcriptase kit (Tiangen Biotech Co., Ltd., Beijing, China), according to the manufacturer's protocol. PCR primer sequences are presented in Table I, and annealing and thermocycling conditions are presented in Table II. The denaturation for each gene was performed at $94^{\circ} \mathrm{C}$ for $1 \mathrm{~min}$, and extension was performed at $72^{\circ} \mathrm{C}$ for $1 \mathrm{~min}$. Relative mRNA levels were calculated based on the ratios of detected gene $/ \beta$-actin using Quantity One ${ }^{\circledR}$ Software (version 4.2; Bio-Rad Laboratories, Inc., Hercules, CA, USA).

Protein expression of $I L-8$ receptors in HeLa cells using western blot analysis. Total protein extracts from HeLa cells were prepared with a cell lysis buffer [50 mM Tris- $\mathrm{HCl}$ (pH 7.5), $150 \mathrm{mM} \mathrm{NaCl}, 1 \mathrm{mM}$ sodium-EDTA, $1 \mathrm{mM}$ EDTA, $1 \%$ (v/v) TritonX-100, $2.5 \mathrm{mM}$ sodium pyrophosphate, $1 \mathrm{mM} \beta$-glycerophosphate, $1 \mathrm{mM}$ Na3VO4, $1 \mathrm{mM} \mathrm{NaF}$, $1 \mu \mathrm{g} / \mathrm{ml}$ leupeptin and $1 \mathrm{mM}$ PMSF] described previously (13). Following quantification of protein concentration using the BCA assay kit (Wuhan Boster Biological Technology, Ltd., Wuhan, China), $40 \mu \mathrm{g}$ of total proteins per lane were resolved by $12 \%$ SDS-PAGE and transferred onto a polyvinylidene fluoride membrane (EMD Millipore, Billerica, MA, USA). Following blocking with commercial blocking buffer (Wuhan Boster Biological Technology, Ltd.) at $37^{\circ} \mathrm{C}$ for $1 \mathrm{~h}$, the membranes were probed with rabbit anti-human IL-8RA/B monoclonal antibody (cat. no. sc-30008; dilution, 1:500; Santa Cruz Biotechnology, Inc., Dallas, TX, USA) or mouse anti- $\beta$-actin monoclonal antibody (cat. no. sc-130300; dilution, 1:3,000; Santa Cruz Biotechnology, Inc.) at $4^{\circ} \mathrm{C}$ overnight. Following washing with TBST, the membranes were incubated with goat anti-rabbit IgG (cat. no. BA1054; dilution, 1:1,000; Wuhan Boster Biological Technology, Ltd.) or goat anti-mouse IgG (cat. no. BA1050; dilution, 1:1,000; Wuhan Boster Biological Technology, Ltd.) at $37^{\circ} \mathrm{C}$ for $1 \mathrm{~h}$. Signals were detected using Western Bright ECL reagent (cat. no. 151030-16; Advansta, Menlo Park, CA, USA) and
Blotting System (Bio-Rad Laboratories, Inc.). Band densities were subsequently analyzed using Quantity One ${ }^{\circledR}$ Software (version, 4.2; Bio-Rad Laboratories, Inc.).

Expression levels of IL-8 in a cervical tissue microarray using immunohistochemistry. A tissue microarray (Alenabio, Xi'an, China) containing 40 normal uterine cervical tissue samples and $40 \mathrm{UCC}$ tissue samples were performed to determine the expression of IL-8. In the UCC group, all the cancer samples were confirmed as squamous cell carcinoma. Expression levels of IL-8 in the tissue microarray were investigated according to a protocol described previously (14). Briefly, after deparaffinizing and rehydrating, endogenous peroxidase in the microarray was deactivated using 3\% dilution hydrogen peroxide at room temperature for $15 \mathrm{~min}$. Antigen retrieval was performed by incubating the microarray with $10 \mathrm{mM}$ citrate buffer $(\mathrm{pH} \mathrm{6.0}$; cat. no. AR0024; Wuhan Boster Biological Technology, Ltd.) for $30 \mathrm{~min}$ at low power microwave, and nonspecific binding sites were blocked with normal rabbit-serum (cat. no. C1404; Shanghai Westang Bio-Tech Co., Ltd.) at $37^{\circ} \mathrm{C}$ for $20 \mathrm{~min}$. Subsequently, the tissue microarray was incubated with mouse anti-IL-8 monoclonal antibody (1:50; Santa Cruz Biotechnology, Inc.) at $4^{\circ} \mathrm{C}$ overnight, and was then treated with a Streptavidin-Biotin Complex kit (cat. no. SA1050; Wuhan Boster Biological Technology, Ltd.). To quantify the protein level, the average optical density in a high-power field (magnification, $\mathrm{x} 400$ ) was detected using BI-2000 Medicine Image Analysis Software (Chengdu Taimeng Technology Co., Ltd., Chengdu, China). Strong and weak immunostaining were defined, respectively, as average optical values of $\geq 210$ and $\leq 180$.

Effect of exogenous IL-8 on the proliferation of HeLa cells. HeLa cells were seeded in 96 -well plates $\left(1.5 \times 10^{3}\right.$ cells/well $)$ and incubated in RPMI-1640 medium supplemented with $10 \% \mathrm{FBS}$ overnight at $37^{\circ} \mathrm{C}$ in a $5 \% \mathrm{CO}_{2}$ incubator. Subsequently, cells were divided into five groups by removing old culture medium and replacing it with different conditioning medium containing $0.1 \%$ bovine serum albumin (Wuhan Boster Biological Technology, Ltd.) and IL-8 (PeproTech, Inc., Rocky Hill, NJ, USA) at final concentrations of 0, 20, 40, 60 and $80 \mathrm{ng} / \mathrm{ml}$, respectively. Following a 72-h incubation period, Cell Counting kit-8 (CCK-8; Boster Biological Technology, Pleasanton, CA, USA) was added to each well (10 $\mu 1$ per well). Following incubation in a $5 \% \mathrm{CO}_{2}$ incubator at $37^{\circ} \mathrm{C}$ for $1 \mathrm{~h}$, absorbance was detected at $450 \mathrm{~nm}$ using a microplate reader (BioTek Instruments, Inc., Winooski, VT, USA).

Effects of exogenous IL-8 on migration of HeLa cells. A Transwell migration assay was performed using a 24-well chamber (Corning Incorporated, Corning, NY, USA). Briefly, HeLa cells in Transwell units were divided into three groups and $5 \times 10^{4}$ cells/well were plated onto the top surface of the upper chamber containing $100 \mu 1$ RPMI-1640 medium without FBS. In the lower chamber, RPMI-1640 medium with 5\% FBS and IL-8 (PeproTech, Inc.) at final concentrations of 0,40 and $60 \mathrm{ng} / \mathrm{ml}$ for the three groups were added, respectively. Following a $24 \mathrm{~h}$ incubation period at $37^{\circ} \mathrm{C}$ in a $5 \% \mathrm{CO}_{2}$ incubator, non-migratory cells were 
Table I. Primer sequences for genes used in reverse transcription-polymerase chain reaction experiments.

\begin{tabular}{lll}
\hline Gene & \multicolumn{1}{c}{ Forward primer } & \multicolumn{1}{c}{ Reverse primer } \\
\hline$\beta$-actin & 5'-AGAAAATCTGGCACCACACC-3' & 5'-CTCCTTAATGTCACGCACGA-3' \\
IL-8 & 5'-ACATACTCCAAACCTTTCCACC-3' & 5'-AAAACTTCTCCACAACCCTCTG-3' \\
IL-8RA & 5'-GACCTACTCTTTGCCCTGAC-3' & 5'-AACACCATCCGCCATTTT-3' \\
IL-8RB & 5'-GGAAACTCCCTCGTGATG-3' \\
ERK & 5'-CTTCTCGCCTCAGTTCGC-3' & 5'-CAGGAATGTGCCAAAAAT-3' \\
NUMB & 5'-AAACGCCAACTATCCCTACGC-3' & 5'-CTCCTGGATGCTTGTCTGGTAA-3' \\
\hline
\end{tabular}

IL, interleukin; ERK, extracellular-signal-regulated kinase; NUMB, endocytic adaptor protein.

Table II. Specific thermocycling conditions used for reverse transcription-polymerase chain reactions.

\begin{tabular}{lcc}
\hline Gene & Annealing temperature, ${ }^{\circ} \mathrm{C}$ & Number of cycles \\
\hline$\beta$-actin & 54 & 25 \\
IL-8 & 57 & 38 \\
IL-8RA & 55 & 33 \\
IL-8RB & 58 & 33 \\
ERK & 55.6 & 30 \\
NUMB & 59 & 35
\end{tabular}

All annealing was performed for $30 \mathrm{sec}$. IL, interleukin; ERK, extracellular-signal-regulated kinases.

removed with a cotton swab and filters containing migratory cells were fixed and stained with $0.1 \%$ crystal violet for $30 \mathrm{~min}$ at room temperature. Migratory cells were counted in $\geq 5$ randomly selected fields using brightfield microscopy (magnification, x100).

Statistical analysis. All data are expressed as the mean \pm standard deviation. Data were analyzed using one-way analysis of variance and q-test. $\mathrm{P}<0.05$ was considered to indicate a statistically significant difference.

\section{Results}

mRNA expression of $I L-8$ and its receptors in HeLa cells determined using $R T-P C R$. To explore the potential function of IL- 8 in HeLa cells, the present study determined IL- 8 mRNA expression and its receptors using RT-PCR. Results demonstrated that IL-8 and its receptors were expressed in HeLa cells, and IL-8RA mRNA levels were significantly upregulated in HeLa cells compared with those of IL-8RB (Fig. 1A).

Protein expression of $I L-8$ receptors in HeLa cells determined using western blot analysis. On the basis of results obtained from RT-PCR, western blot analysis was utilized to determine the expression levels of IL-8 receptors (IL-8RA/RB) in HeLa cells. Consistent with RT-PCR results, there was a statistically significant increase in the protein expression of IL-8RA compared with that of IL-8RB (Fig. 1B).
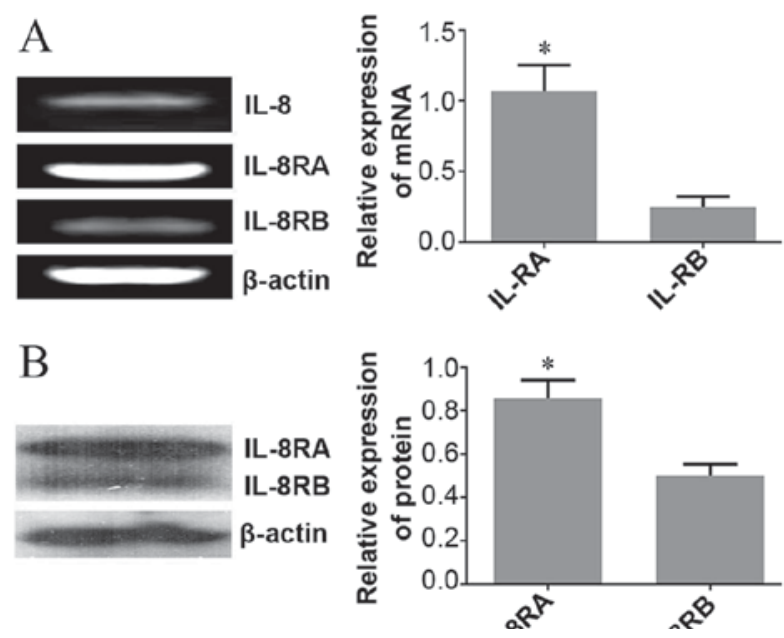

Figure 1. Expression levels of IL-8 and its receptors IL-8RA and IL-8RB in HeLa cervical carcinoma cells. (A) An RT-PCR assay demonstrated that IL-8, IL-8RA and IL-8RB at the mRNA level were expressed in HeLa cells. IL-8RA was significantly increased compared with IL-8RB in HeLa cells $\left({ }^{*} \mathrm{P}<0.05\right)$. (B) Expression levels detected using western blot analysis, IL-8RA protein levels in HeLa cells were significantly upregulated, which was consistent with RT-PCR results ( $\mathrm{P}<0.05)$. RT-PCR, reverse transcription-polymerase chain reaction; IL, interleukin; IL-8R, IL-8 receptor.

Expression levels of IL-8 determined using a human uterine cervical tissue microarray. To further investigate the clinical significance of IL-8 in UCC, a tissue microarray was used to compare the expression of IL-8 in normal uterine cervical tissues and UCC tissues (Fig. 2). Compared with the normal uterine cervical tissues, the expression levels of IL-8 in UCC tissues were increased in terms of average optical values. No association between the increased expression of IL-8 and age or clinical stage of UCC was identified using the assay (Table III).

Effect of exogenous IL-8 on the proliferation of HeLa cells determined using the CCK-8 assay. A CCK- 8 assay was utilized to explore the proliferation of HeLa cells treated with different concentrations of exogenous IL-8. Results demonstrated that the proliferation of HeLa cells were markedly enhanced as the concentration of IL-8 increased (40, 60 and $80 \mathrm{ng} / \mathrm{ml})$. The absorbance reached a maximum $(1.341 \pm 0.056)$ when the concentration of IL-8 was $60 \mathrm{ng} / \mathrm{ml}$. The proliferation rate decreased in HeLa cells treated with 40 and $80 \mathrm{ng} / \mathrm{ml}$ exogenous IL-8, compared with HeLa cells 
treated with $60 \mathrm{ng} / \mathrm{ml}$ exogenous IL-8. However, no statistically significant difference was identified (Fig. 3A).

Effect of exogenous IL-8 on migration of HeLa cells determined using a Transwell assay. Analysis of migration indicated that $\mathrm{HeLa}$ cells treated with 40,60 and $80 \mathrm{ng} / \mathrm{ml}$ exogenous IL-8 migrated faster compared with untreated HeLa cells. The migratory efficiency of HeLa cells treated with $60 \mathrm{ng} / \mathrm{ml}$ exogenous IL-8 was the greatest; however, no significant difference between HeLa cells treated with 40, 60 and $80 \mathrm{ng} / \mathrm{ml}$ exogenous IL-8 was identified (Fig. 3B and C). These results were in agreement with the CCK-8 proliferation assay.

Exogenous IL-8 regulates the expression of carcinogenesis-associatedgenesinHeLacells determinedusing $R T-P C R$. To elucidate the underlying molecular mechanism(s) of IL-8-associated tumorigenesis in UCC, RT-PCR was performed in order to investigate whether IL-8 regulated the expression of carcinogenesis-associated genes in HeLa cells. Results demonstrated that the expression of NUMB at the mRNA level were markedly inhibited following administration of $60 \mathrm{ng} / \mathrm{ml}$ exogenous IL-8, and the expression of IL-8RA, IL-8RB and extracellular-signal-regulated kinases (ERKs) were upregulated when cells were treated with 40 and $60 \mathrm{ng} / \mathrm{ml}$ exogenous IL-8 compared with untreated cells (Fig. 4A and B).

\section{Discussion}

IL-8, also referred to as CXCL8, is a cytokine of the CXC chemokine family that is associated with inflammatory and immune responses, and is also an important biomarker for a range of diseases including various types of cancer. In the present study, the function of IL-8 in UCC was investigated and novel results included: IL- 8 and its receptors may be involved in the development and progression of UCC, exogenous IL-8 promotes the carcinogenic potential of HeLa cells by upregulating the expression of its receptors IL-8RA, IL-8RB and ERK, and downregulating the expression of NUMB.

IL-8 exerts its biological effects via G-protein/adenylate cyclase and G-protein/phospholipase $\mathrm{C}$ signaling pathways by binding with its receptors IL-8RA and IL-8RB $(4,15)$. IL-8 RA and IL-8RB exhibit marked affinity for IL-8, and the presence of IL- 8 and its receptors during tumor development and progression is a relatively common occurrence (16). IL-8RA has an increased specificity for IL-8 and a decreased affinity for other cytokines, whereas IL-8RB is less specific for IL-8 but is able to bind with other cytokines including CXCL3 and CXCL5 (17). Therefore, this may be the primary reason for the increase in the expression levels of IL-8RA compared with IL-8RB in HeLa cells. The IL-8/IL-8 receptor axis has been identified to be associated with various types of human cancer including pilomatricoma and hepatoma (18-20). However, the underlying molecular mechanisms by which IL-8 and its receptors are involved in UCC remain unclear. In the present study, results obtained from in vitro and in vivo experiments demonstrated that IL-8 was expressed in HeLa cells and UCC tissues, and the expression levels of IL-8 in UCC tissue were significantly increased compared with those in normal uterine cervical tissue; however, no association between overexpression of IL-8 with patient age, stage or clinical classification of UCC
Table III. Expression of IL-8 in a cervical tissue microarray.

\begin{tabular}{lcc}
\hline Clinical parameter & Average optical density & P-value \\
\hline Cervical cancer tissues & $202.60 \pm 7.51$ & $<0.01$ \\
Normal cervical tissues & $181.23 \pm 12.46$ & \\
TNM stage & & $>0.05$ \\
I & $202.54 \pm 6.77$ & \\
II & $202.01 \pm 7.88$ & \\
III & $203.14 \pm 7.39$ & \\
Age, years & & $>0.05$ \\
$\leq 50$ & $202.58 \pm 7.35$ & \\
$\geq 51$ & $202.62 \pm 7.76$ & \\
\hline
\end{tabular}

The protein level of IL-8 in a high-power field (magnification, $x 400$ ) was calculated based upon the average optical density detected using a medicine image analysis software. IL, interleukin; TNM, tumor node metastasis.

was identified in the present study. In addition, IL- 8 receptors were expressed at the mRNA and protein levels in HeLa cells. Therefore, results demonstrated that IL- 8 and its receptors may contribute to the development of UCC. Previous reports demonstrated that the overexpressed IL-8 and its receptors produced by tumor cells and the tumor microenvironment promoted tumor development by stimulating angiogenesis and increasing the capacity of cellular adhesion, migration and proliferation, and causing chemotherapy resistance (21-23). In the present study, a CCK- 8 assay and Transwell assay were performed to study the effects of different concentrations of exogenous IL-8 on the malignant behavior of HeLa cells. As HeLa cells were exposed to increasing concentrations of IL-8, there was also an increase in the proliferation and migration. In addition, increasing levels of IL-8RA and IL-8RB were observed, and this further confirmed the carcinogenic potential of the IL-8/IL-8 receptor axis in UCC.

The ERK signaling pathway transmits mitogenic signals and regulates numerous cellular functions, including proliferation and differentiation $(24,25)$. In order to adapt to internal and external environmental stimuli, the ERK cascade must be strictly regulated in order to produce the correct biological response $(26,27)$. An aberrant ERK cascade is commonly observed in human tumors, and is accompanied by the deregulation of proliferation and malignant transformation. Recent studies have identified that the ERK signaling pathway inhibits the apoptosis of tumor cells by influencing the mitochondrial apoptosis pathway, for example, the ERK signaling pathway can exert its anti-apoptotic control by non-activation of certain pro-apoptotic kinases, including Janus kinase and p38 mitogen activated protein kinase. The increased ERK activity is associated with invasion and metastasis in cholangiocarcinoma and breast carcinoma $(28,29)$. However, conflicting results suggest that the activation of ERK may exert diverse effects in a different microenvironment, for example, ERK may be able to promote cell apoptosis by enhancing the activities of the apoptotic proteins caspase-9 and caspase-3 (30,31). Clinically, therapeutic agents targeting the ERK signaling pathway may also lead to the development of drug resistance $(11,32)$. The 

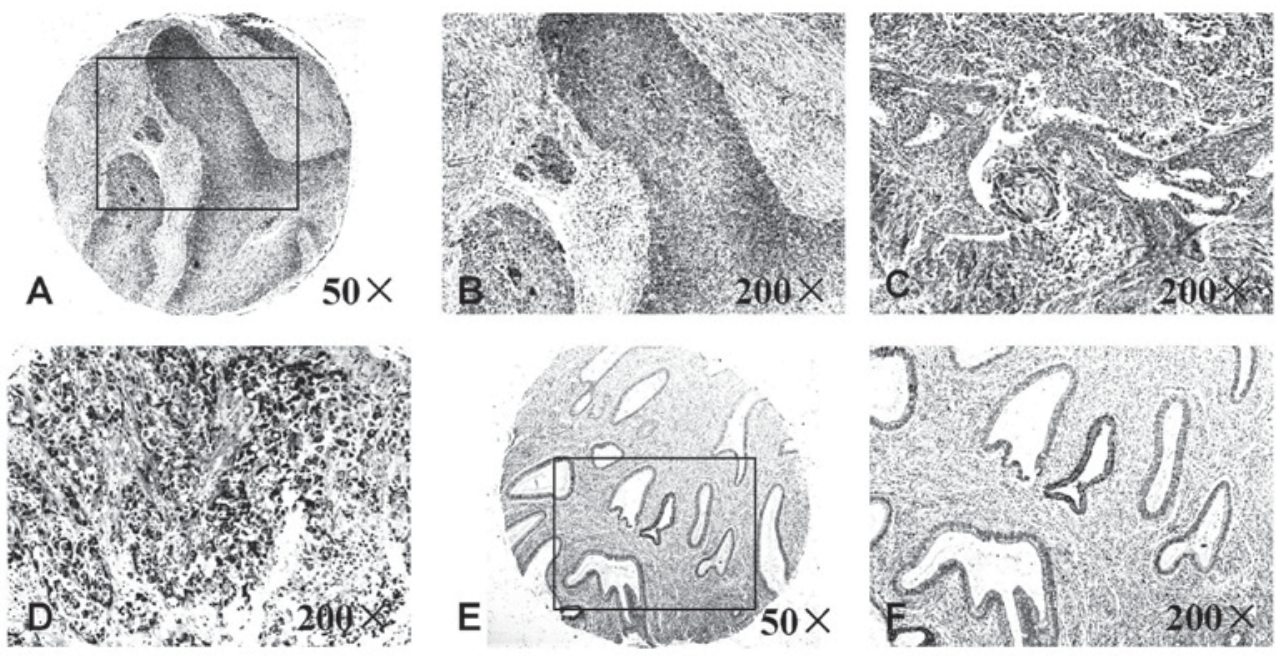

Figure 2. Expression levels of IL-8 protein are associated with cervical carcinoma progression determined using immunohistochemical staining. Strong immunostaining of IL-8 was presentin (A) Grade 1 (magnification, x50), (B) grade 1 (magnification, x200), (C) grade 2 (magnification, x200) and (D) grade 3 (magnification, x200) uterine cervical cancer tissue. Weak immunostaining of IL-8 was present in (E) normal uterine cervical tissue (magnification, x50) and (F) normal uterine cervical tissue (magnification, x200). IL, interleukin.

A

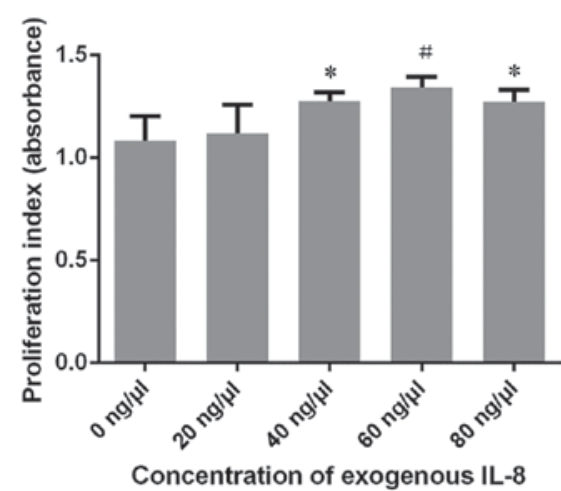

$\mathrm{B}$

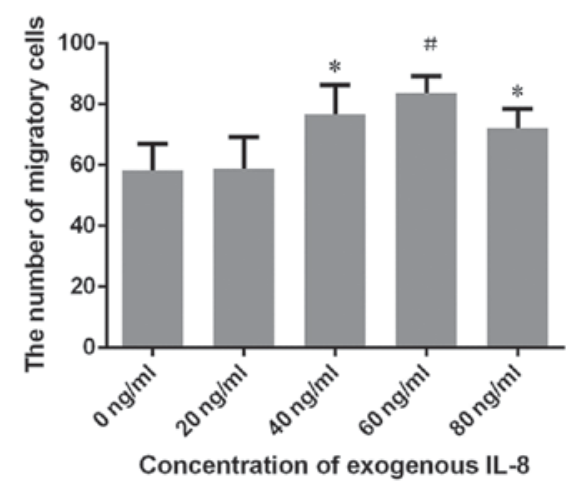

$\mathrm{C}$

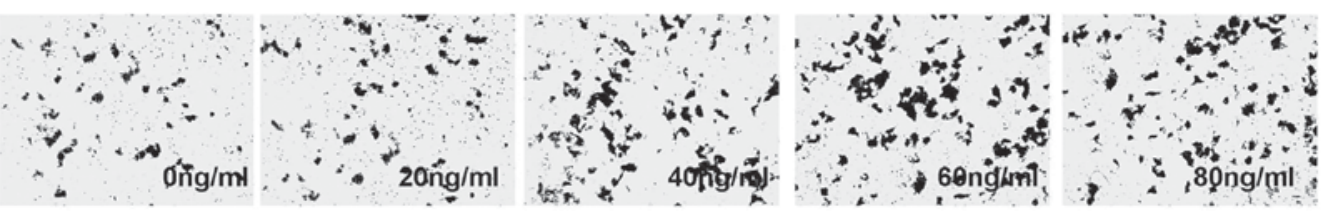

Figure 3. Exogenous IL-8 is affects proliferation and migration in HeLa cells. CCK-8 and Transwell assays demonstrated that an increase in exogenous IL-8 concentration is able to promote the (A) proliferation and (B and C) migration of HeLa cells in a concentration-dependent manner $\left({ }^{*} \mathrm{P}<0.05\right.$, $\left.{ }^{\#} \mathrm{P}<0.01\right)$. At concentrations $>60 \mathrm{ng} / \mathrm{ml}$, the ability to promote proliferation and migration starts to decline; however, this decrease was not statistically significant. CCK-8, Cell Counting kit-8; IL, interleukin.

A

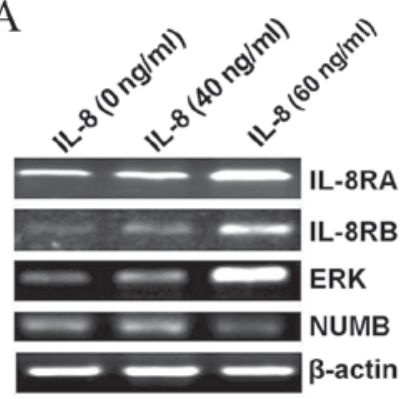

$\mathrm{B}$

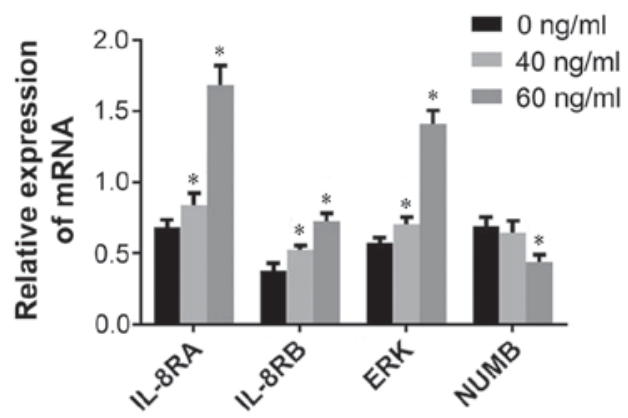

Figure 4. Exogenous IL-8 regulates the expression of carcinogenesis-associated genes in HeLa cells. (A) Expression of IL-8RA, IL-8RB, ERK and NUMB was analyzed using RT-PCR. (B) Exogenous IL-8 (40 and $60 \mathrm{ng} / \mathrm{ml}$ ) is able to significantly upregulate the expression of IL-RA, IL-RB and ERK genes, whereas $60 \mathrm{ng} / \mathrm{ml}$ of exogenous IL-8 downregulates the level of NUMB ("P<0.01). IL, interleukin; ERK, extracellular-signal-regulated kinase; RT-PCR, reverse transcription-polymerase chain reaction; IL-8R, IL-8 receptor; NUMB, endocytic adaptor protein. 
results of the present study demonstrated that exogenous IL-8 increased proliferation and migration in HeLa cells, and upregulated the expression of ERK simultaneously.

Furthermore, the results of the present study also demonstrated a decrease in NUMB mRNA expression in HeLa cells treated with exogenous IL-8. The endocytic adaptor protein NUMB, an intrinsic regulator of cell fate determination, inhibits the Notch signaling pathway and the p53/p21 axis, contributing to the control of asymmetric cell division, maintaining stem cell compartments and representing a mechanism of tumor suppression (33-35). NUMB expression is frequently decreased in tumors, and NUMB dysfunction or loss leads to differentiation defects and serves a crucial function in mammary tumorigenesis $(36,37)$. The present study therefore determined that the downregulation of NUMB expression by exogenous IL-8 was one explanation for the improvement of migration and proliferation in HeLa cells.

In conclusion, the results of the present study demonstrated that the underlying molecular mechanisms which regulate the expression of ERK and NUMB are affected by exogenous IL-8, and are associated with an increase in the migration and proliferation of HeLa cells. These results demonstrate that inhibition of the IL-8/IL-8 receptor axis may be a specific target for the treatment of UCC.

\section{Acknowledgements}

The present study was supported by the National Nature Science Foundation of China (grant no. 81272854), Nature Science Foundation of Heilongjiang Province (grant no. D201129), Science and Innovation Team Foundation of Education Department of Heilongjiang Province (grant no. cxtd-2016-03), President Innovation and Entrepreneurship Foundation of Jiamusi University (grant no. xzyf2014-12) and the Innovation and Entrepreneurship Training Program for College Students of Heilongjiang Province (grant no. 201410222036).

\section{References}

1. Torre LA, Bray F, Siegel RL, Ferlay J, Lortet-Tieulent J and Jemal A: Global cancer statistics, 2012. CA Cancer J Clin 65: 87-108, 2015

2. Miyamoto Y, Nakagawa S, Wada-Hiraike O, Seiki T, Tanikawa M, Hiraike H, Sone K, Nagasaka K, Oda K, Kawana K, et al: Sequential effects of the proteasome inhibitor bortezomib and chemotherapeutic agents in uterine cervical cancer cell lines. Oncol Rep 29: 51-57, 2013.

3. Hernández-HernándezDM,Apresa-García TandPatlán-PérezRM: Epidemiological overview of uterine cervical cancer. Rev Med Inst Mex Seguro Soc 53 (Suppl 2): S154-S161, 2015.

4. Jiang WG, Sanders AJ, Ruge F and Harding KG: Influence of interleukin-8 (IL-8) and IL-8 receptors on the migration of human keratinocytes, the role of PLC- $\gamma$ and potential clinical implications. Exp Ther Med 3: 231-236, 2012.

5. Stronach EA, Cunnea P, Turner C, Guney T, Aiyappa R, Jeyapalan S, de Sousa CH, Browne A, Magdy N, Studd JB, et al: The role of interleukin-8 (IL-8) and IL-8 receptors in platinum response in high grade serous ovarian carcinoma. Oncotarget 6: 31593-31603, 2015.

6. Siegel R, Ma J, Zou Z and and Jemal A: Cancer statistics, 2014. CA Cancer J Clin 64: 9-29, 2014.

7. Ferlay J, Steliarova-Foucher E, Lortet-tieulent J, Rosso S, Coebergh JW, Comber H, Forman D and Bray F: Cancer incidence and mortality patterns in Europe: Estimates for 40 countries in 2012. Eur J Cancer 49: 1374-1403, 2013.
8. Brat DJ, Bellail AC and Van Meir EG: The role of interleukin-8 and its receptors in gliomagenesis and tumoral angiogenesis. Neuro Oncol 7: 122-133, 2005.

9. Singh RK and Lokeshwar BL: The IL-8-regulated chemokine receptor CXCR7 stimulates EGFR signaling to promote prostate cancer growth. Cancer Res 71: 3268-3277, 2011.

10. Russo RC, Garcia CC, Teixeira MM and Amaral FA: The CXCL8/IL-8 chemokine family and its receptors in inflammatory diseases. Expert Rev Clin Immunol 10: 593-619, 2014.

11. Araki S, Omori Y, Lyn D, Singh RK, Meinbach DM, Sandman Y, Lokeshwar VB and Lokeshwar BL: Interleukin-8 is a molecular determinant of androgen independence and progression in prostate cancer. Cancer Res 67: 6854-6862, 2007.

12. Sims LB, Curtis LT, Frieboes HB and Steinbach-Rankins JM: Enhanced uptake and transport of PLGA-modified nanoparticles in cervical cancer. J Nanobiotechnology 14: 33, 2016.

13. Shen L, Wen N, Xia M, Zhang YU, Liu W, Xu YE and Sun L: Calcium efflux from the endoplasmic reticulum regulates cisplatin-induced apoptosis in human cervical cancer HeLa cells. Oncol Lett 11: 2411-2419, 2016.

14. Gui SL, Teng LC, Wang SQ, Liu S, Lin YL, Zhao XL, Liu L, Sui HY, Yang Y, Liang LC, et al: Overexpression of CXCL3 can enhance the oncogenic potential of prostate cancer. Int Urol Nephrol 48: 701-709, 2016.

15. Tsai YJ, Hao SP, Chen CL and Wu WB: Thromboxane A2 regulates CXCL1 and CXCL8 chemokine expression in the nasal mucosa-derived fibroblasts of chronic rhinosinusitis patients. PLoS One 11: e0158438, 2016.

16. Liu Q, Li A, Tian Y, Wu JD, Liu Y, Li T, Chen Y, Han X and Wu K: The CXCL8-CXCR1/2 pathways in cancer. Cytokine Growth Factor Rev 31: 61-71, 2016.

17. Singh JK, Simões BM, Howell SJ, Farnie G and Clarke RB: Recent advances reveal IL-8 signaling as a potential key to targeting breast cancer stem cells. Breast Cancer Res 15: 210, 2013.

18. Cianga CM, Cianga P, Dumitrescu GF and Sava A: IL-8, IL-8RA (CXCR1) and IL-8RB (CXCR2) expression in pilomatricoma. Rom J Morphol Embryol 57: 59-64, 2016.

19. Fernando RI, Castillo MD, Litzinger M, Hamilton DH and Palena C: IL-8 signaling plays a critical role in the epithelial-mesenchymal transition of human carcinoma cells. Cancer Res 71: 5296-5306, 2011.

20. Aravalli RN and Greten TF: FoxC1: Novel regulator of inflammation-induced metastasis in hepatocellular carcinoma. Gastroenterology 149: 861-863, 2015.

21. Wu D, Tao J, Ding J, Qu P, Lu Q and Zhang W: Interleukin-11, an interleukin-6-like cytokine, is a promising predictor for bladder cancer prognosis. Mol Med Rep 7: 684-688, 2013.

22. Xiao YC, Yang ZB, Cheng XS, Fang XB, Shen T, Xia CF, Liu P, Qian HH, Sun B, Yin ZF and Li YF: CXCL8, overexpressed in colorectal cancer, enhances the resistance of colorectal cancer cells to anoikis. Cancer Lett 361: 22-32, 2015.

23. Mellado M, Rodríguez-Frade JM, Mañes S and Martínez-A C: Chemokine signaling and functional responses: The role of receptor dimerization and TK pathway activation. Annu Rev Immunol 19: 397-421, 2001

24. Liu F, Zheng S, Liu T, Liu Q, Liang M, Li X, Sheyhidin I, Lu X and Liu W: MicroRNA-21 promotes the proliferation and inhibits apoptosis in Eca109 via activating ERK1/2/MAPK pathway. Mol Cell Biochem 381: 115-125, 2013.

25. Palena C, Hamilton DH and Fernando RI: Influence of IL-8 on the epithelial-mesenchymal transition and the tumor microenvironment. Future Oncol 8: 713-722, 2012.

26. Lake D, Corrêa SA and Müller J: Negative feedback regulation of the ERK1/2 MAPK pathway. Cell Mol Life Sci 73: 4397-4413, 2016.

27. Bastida MF, Sheth R and Ros MA: A BMP-Shh negative-feedback loop restricts Shh expression during limb development. Development 136: 3779-3789, 2009.

28. Murphy C, McGurk M, Pettigrew J, Santinelli A, Mazzucchelli R, Johnston PG, Montironi R and Waugh DJ: Nonapical and cytoplasmic expression of interleukin-8, CXCR1, and CXCR2 correlates with cell proliferation and microvessel density in prostate cancer. Clin Cancer Res 11: 4117-4127, 2005

29. MacManus CF, Pettigrew J, Seaton A, Wilson C, Maxwell PJ, Berlingeri S, Purcell C, McGurk M, Johnston PG and Waugh DJ: Interleukin-8 signaling promotes translational regulation of cyclin $\mathrm{D}$ in androgen-independent prostate cancer cells. Mol Cancer Res 5: 737-748, 2007. 
30. Venkatakrishnan G, Salgia R and Groopman JE: Chemokine receptors CXCR-1/2 activate mitogen-activated protein kinase via the epidermal growth factor receptor in ovarian cancer cells. J Biol Chem 275: 6868-6875, 2000.

31. Luppi F, Longo AM, de Boer WI, Rabe KF and Hiemstra PS: Interleukin-8 stimulates cell proliferation in non-small cell lung cancer through epidermal growth factor receptor transactivation. Lung Cancer 56: 25-33, 2007.

32. Kawamura M, Toiyama Y, Tanaka K, Saigusa S, Okugawa Y, Hiro J, Uchida K, Mohri Y, Inoue Y and Kusunoki M: CXCL5, a promoter of cell proliferation, migration and invasion, is a novel serum prognostic marker in patients with colorectal cancer. Eur J Cancer 48: 2244-2251, 2012.

33. Tosoni D, Zecchini S, Coazzoli M, Colaluca I, Mazzarol G, Rubio A, Caccia M, Villa E, Zilian O, Di Fiore PP and Pece S: The Numb/p53 circuitry couples replicative self-renewal and tumor suppression in mammary epithelial cells. J Cell Biol 211: 845-862, 2015.
34. Sajadimajd S, Yazdanparast R and Akram S: Involvement of Numb-mediated HIF-1 $\alpha$ inhibition in anti-proliferative effect of PNA-antimiR-182 in trastuzumab-sensitive and -resistant SKBR3 cells. Tumour Biol 37: 5413-5426, 2016.

35. Faraldo MM and Glukhova MA: Regulating the regulator: Numb acts upstream of p53 to control mammary stem and progenitor cell. J Cell Biol 211: 737-739, 2015.

36. Sheng W, Dong M, Zhou J, Li X, Liu Q, Dong Q and Li F: Cooperation among Numb, MDM2 and p53 in the development and progression of pancreatic cancer. Cell Tissue 354: 521-532, 2013.

37. Rojas A, Liu G, Coleman I, Nelson PS, Zhang M, Dash R, Fisher PB, Plymate SR and Wu JD: IL-6 promotes prostate tumorigenesis and progression through autocrine cross-activation of IGF-IR. Oncogene 30: 2345-2355, 2011. 